\title{
How do public policies respond to spatialized environmental issues? Feedback and perspectives
}

Christine Voiron-Canicio ${ }^{1}$, Emmanuel Garbolino ${ }^{2}$, Nathalie Cecutti ${ }^{3}$, Carlo Lavalle ${ }^{4}$ and José Juan Hernández Chávez ${ }^{5}$

${ }^{1}$ Université Côte d'Azur, CNRS, Laboratory ESPACE, Nice, France, ${ }^{2}$ Climpact Data Science, Nova Sophia-Regus Nova, Sophia Antipolis, France, ${ }^{3}$ Ministry of the Ecological and Solidary Transition, Paris, France, ${ }^{4}$ European Commission-Joint Research Center, Ispra, Italy,

${ }^{5}$ Ministry of Environment and Natural Resources, Mexico

13.1 Feedback on the Sustainable Territory 2030 prospective program carried out by the Prospective Mission of the French Ministry in charge of Sustainable Development and the Environment

Interview with Natahlie Cecutti, conducted on February 7, 2019

Natahlie Cecutti is State architect and urban planner in chief. After 20 years of territorial actions in connection with land development and urban planning in the private and parapublic sectors, she led the Prospective Mission of the Ministry in charge of Sustainable Development and the Environment from 2011 to 2017. She is currently an expert to the Head of the Ministry of the Ecological and Solidary Transition's research department for 
developing relations with non-State actors on research issues and she also coordinates the European research and innovation framework programs "Horizon 2020" and the future "Horizon Europe," on behalf of the ministry.

How was the spatial dimension integrated into your prospective works? Was it introduced implicitly?

N.C.: I will take the example of the work we carried out on the Sustainable Territory 2030 program (Box 13.1) when I was at the Prospective Mission, the MEDDE's ${ }^{1}$ seminal task, initiated in part by Jacques Theys ${ }^{2}$ on the principles, bearing in mind that it consisted in integrating the notion of sustainable development into the development of territories (Commissariat Général au Développement Durable, 2013). Indeed, from 2010 onwards, the main objective was to move to a second phase of land development, which until then was mostly devoted to organizing infrastructure and facilities. Jacques Theys and I realized that the global concern about the environment should be reflected in a different manner in the territories.

\section{How to move from sustainable development to sustainable territory?}

N.C.: Well. When he left the Prospective Mission, in the context of the prospective work that we were carrying out, we looked into the way of going from the idea of sustainable development to the territory. How to apply the concept to the territory? We thought that, in the main themes of Sustainable Territory 2030, we had to work in a concrete manner on some subdimensions, subprograms included in the fields covered by the Ministry of the Environment. That's how we decided to work on the biodiversity program for 2030 and on Aqua 2030 relating to continental waters (CGDD website).

\section{The program Sustainable Territory 2030}

The aim of the program Sustainable Territory 2030, conducted by the French Ministry of the Environment's Prospective Mission between 2010 and 2012, was threefold:

To prepare territories to the challenges of CC, social cohesion, biodiversity and green growth;

To set out the visions of a sustainable development for these territories;

To put forward strategic recommendations.

(Continued)

${ }^{1}$ MEDDE: Ministry of Ecology, Sustainable Development, and Energy (France).

2 Jacques Theys was Head of prospective planning at the Ministries of the Environment and of Equipment, scientific director of the French Institute for the Environment, technical advisor for several ministers and copresident of one of the GIEC-IPCC's subgroups. He is vice-president of the Société Française de Prospective and of the Mediterranean Plan Bleu program. 


\section{(Continued)}

The prospective exercise co-constructed by some thirty local stakeholders, was based on a systemic, holistic and multidimensional approach of the dynamics-economic, social, ecological, climate, energy and institutional-and on the scenario method. The prospective group paid much attention to the notions of abrupt change and crisis, as well as to changes depending on territorial contexts.

Two subprograms-Aqua 2030 and Biodiversity and Territory 2030-devised along the same principles, were conducted at the same time.

The subprogram "Biodiversity and Territories 2030": a prospective approach structured in 6 steps

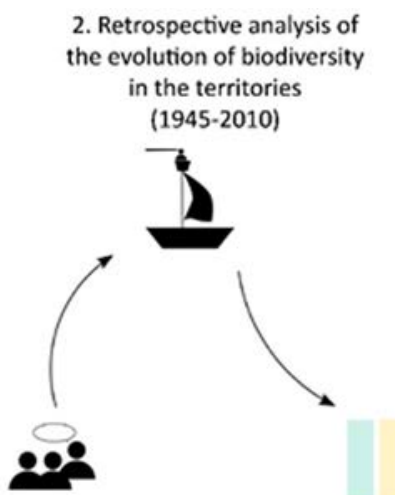

1. The approach's preliminary guidelines and system definition
4. Building micro-scenarios
per component

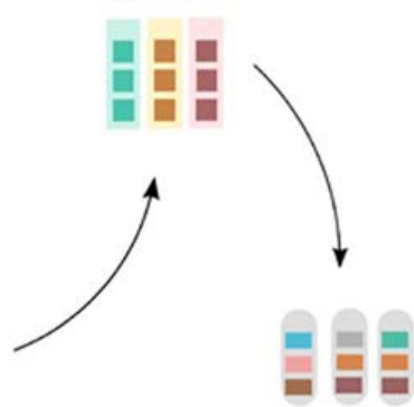

3. Breaking the system down into key components
6. Territorializing
the scenarios
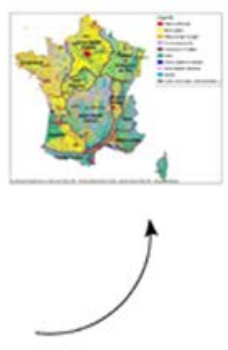

5. Exploring possible combinations and drawing up scenarios

Five global scenarios: Sc. 1 Trend; Sc. 2 Community biodiversity; Sc. 3 Imposed biodiversity; Sc. 4 Ignored biodiversity; Sc. 5 Market biodiversity

Based on: Commissariat Général au Développement Durable, 2013, Biodiversité et Territoires 2030, cinq scénarios d'évolution, synthèse de l'exercice de prospective: volets 1 et 2, p.8. Collection Etudes \& Documents de la Délégation au Développement Durable, n 86, juin 2013.

By conducting the "Water, aquatic environments and sustainable territories 2030" prospective approach, called Aqua 2030, we raised interesting questions. We realized that there were questions of water quantity and quality that had to be addressed in the territories, but that these were not all in the same situation. The differentiation of territories has always been very important in my view. I have always maintained that the question of land development arises on differentiated territories. Each territory has its own components. I'll come back on this notion of components which cross the prospective dimension with the territorial dimension. The components that are specific to the territory, its characteristics, 
are important elements which are not addressed in the same manner when you conduct a prospective work on ways of life, for example.

Within the framework of Aqua 2030, we worked on the question of water governance, the volume of water, water quality, then on the impact of climate change on water supply, etc. I then realized that the water system had its own logic, that is, you are not in similar logics when you are on an upstream spring or in the forming of the first torrential valleys, when you are in an urbanized environment or in a basin of irrigated crops. There is already a logic of systems showing that you are forced to sequence territories. In themselves, these provide the ideas on the way to work on prospective spaces.

More precisely, the work on Aqua 2030 was carried out at the national level. The Ministry was meant to set the tone to territories, starting from a vision of national recommendations, without interfering in any way in regions, départements, and cities, except in the case of prerogative of major general interest. Therefore the difficulty was to find the happy medium between recommendations of a general nature, applicable in the entire national territory, and targeted recommendations for such and such territory, town, etc.

As such, the water environment provided the possibility to determine typologies on a more reduced scale. We thus were able to understand part of the territory with its own logics, via water, to have an influence on good water management, on the reparation of environments, on several components which determine the water system's values, contributions, benefits, or dysfunctions. It was then becoming relevant to try and find the kind of typologies in which the territories could recognize themselves. We defined seven types of water course named "model-systems with territorialized stakes". 3 A collaboration was entered into with Futuribles ${ }^{4}$ and IRSTEA, ${ }^{5}$ the aim being to produce prospective recommendations on these series of territories so that any local councilor could recognize his territory's type and reappropriate the recommendations (Hervieu and Jannès-Ober, 2017). At the same time, five global scenarios concerning water were worked out, integrating not only physical elements but also regulatory-European directives, for example-as well as economic, all elements that have an impact on the territory but are difficult to represent. Once these scenarios had been drawn up, we applied them on each of the seven model systems, representing their effects in the form of a block diagram. ${ }^{6}$

That's how water prospective became territorialized, in a form of innovative and subtle in-between, without any interference in the arrangements made by the communities,

\footnotetext{
3 The seven model systems with territorialized stakes: "Intensive agriculture plain"; "Rural headwaters with high tourist component, Plain-Piedmont"; "Rural headwaters with high tourist component, Mountain"; "River metropolis"; "Coastal metropolis"; "Coastal wetlands"; and "Continental wetlands."

4 An independent center for prospective studies and thinking on possible futures.

5 National research institute in sciences and technologies for the environment and agriculture.

${ }^{6}$ cf. Figure 4.6 in Chapter 4.
} 
because that's the role of the state, while leaving room for interpretation and progress to the communities or territories.

\section{How was this implemented? How did you communicate on this modus operandi?}

N.C.: We didn't do enough popularization or exploitation because it was a subproduct of the Sustainable Territory 2030 approach. We used more or less the same method for the work on biodiversity. France was divided into large biodiversity systems. Fundamentally, the large biodiversity systems are roughly spread over a geography which has not changed much. Although there have been transformations inside, and species have evolved, there are still territorial invariants. We wanted to work on large systems independently from the administrative division.

The two subprograms, Aqua 2030 and Biodiversity 2030, have fed the Sustainable Territory 2030 program. My original intention was to show prospective orientations on a representation of the territories. This problem is a matter of language. How to visually translate, on the map, prospective principles and orientations seriously, that is, with a somewhat more scientific content than a nice drawing? I wanted to push codification a little further and also use modeling. There were three entries: how to make known data speak (modeling), how to make representation tools speak, and how to insert prospective elements, to make them visible and legible by decision-makers in this instance because they are the ones who implement (Fig. 13.1).

I previously had some experience with choremes ${ }^{7}$ on the territory of the Besançon Agglomeration to decipher the principle or prospective orientation of a SCOT, ${ }^{8}$ with the aim of working on the symbol, including both text and image, to make complex notions understood by local authorities. With the Sustainable Territory 2030's “Geoprospective” study to which the ESPACE laboratory contributed, we have achieved an original prospective graphic representation. ${ }^{9}$

Until then, the choreme was only a means of making people understand the ongoing dynamics. You have invented the prospective choreme with ESPACE. What is nowadays your view on this geoprospective work? What operational benefits did you get from it?

N.C.: This work was first and foremost a scientific base. Nowadays, local authorities are very busy enhancing the image of their territory, other tools are being used-marketing, design thinking, which is fine. But if you want to go further and help to decipher the phenomena at work on territories, you require sufficiently stable sources, sufficiently updated and available. We are aware of all the stumbling blocks it entails, especially in a

\footnotetext{
7 A choreme is a geographic model built using a combination of simple graphic forms.

8 SCOT: Coherent Territorial Planning Scheme.

9 In addition to the ESPACE laboratory, the consortium in charge of the Geoprospective study included four consulting firms: GAIAGO, ECOVIA, MOEBIO, and 3Liz.
} 


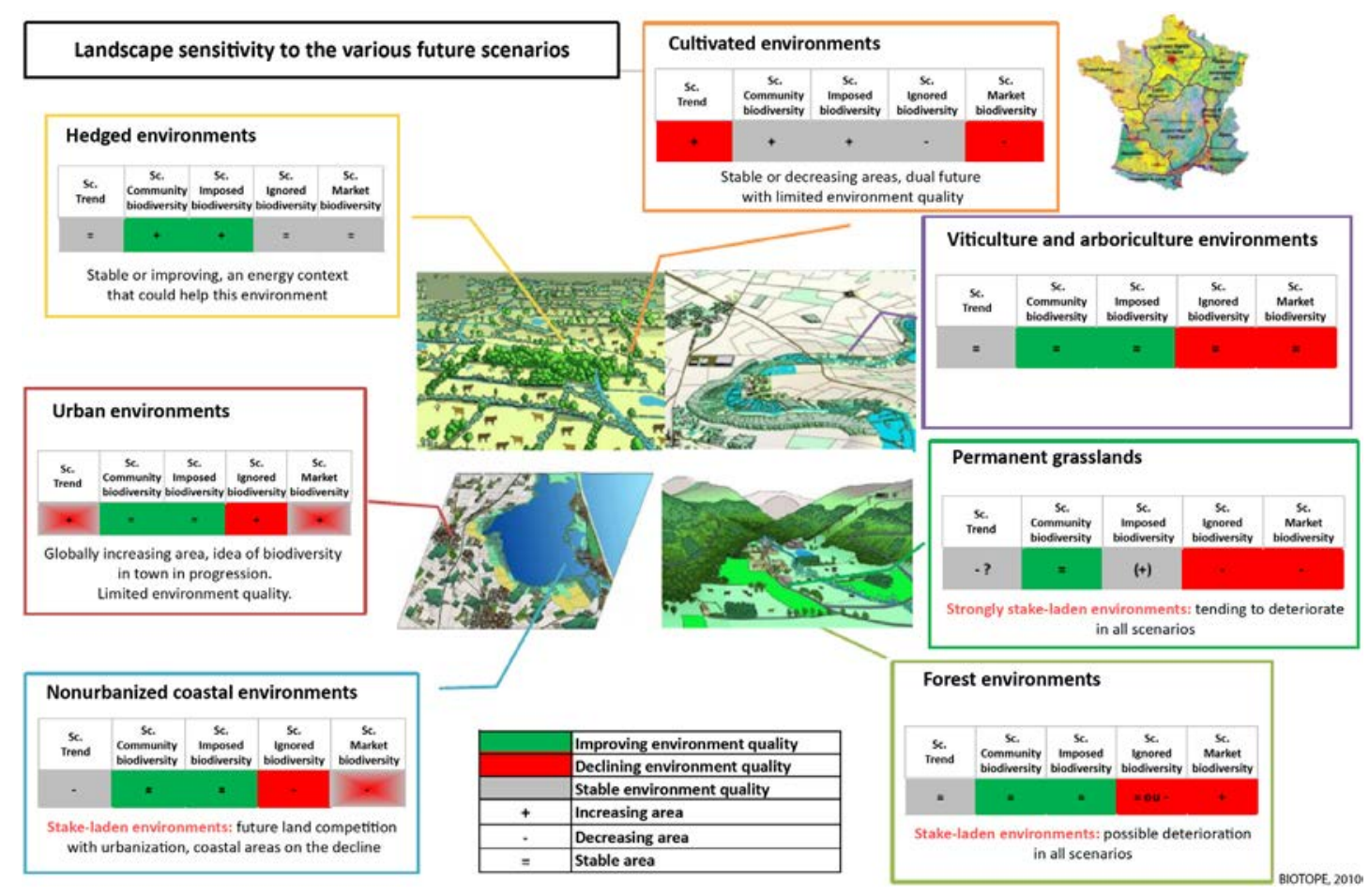

Figure 13.1

Sensitivity of each of the main landscape environments to the content of the five global scenarios. The " + ", "-, " and "= "signs indicate the variation of the landscape's area, and the colors (green, gray, and red) indicate the evolution of these landscapes' ecological quality, still according to the scenarios worked out. A color gradient was used in cases where the evolution of the landscape's quality was uncertain. Source: Commissariat Général au Développement Durable, 2013, p.27.

small community of municipalities. True, we have at our disposal the official manna of European websites and of INSEE (the National Institute for Statistical and Economic studies), which are rather well done, but nevertheless, it would be interesting to have more "indigenous" data banks. Indeed, a local representative who wants to carry out this work on his territory is not always on the right scale in relation to the available source data, and since he lacks these, he doesn't do it. Although he could have data that can help him to mature his project or make progress because he has long known his environment, and he has a technical department where people remember certain things even orally. That's vernacular planning.

When people were seeking my expert advice on such territory for a prospective study, I very often realized by consulting the specifications that the amount set aside for the diagnosis was nearly $50 \%$ of the total amount devoted to the study and that little was left for the stake and the project. A good diagnosis should account for $25 \%$ of the study. 
The local community has practically everything it needs, it has collected numerous data, knows about evolutions. Somehow, it carries out a diagnosis every day. The consulting firm is there as a guide to monitor the process. $30 \%-35 \%$ should be allocated to the stakes, and the rest to the project itself, because that's what gives the orientation and above all, that's where questions of decision arise. Yet, in general it is the opposite: a lot on diagnoses, the stakes are passed over quickly and the questions are not really addressed. I think that the prospective exercise must really be rethought differently in its pace, especially in a territory, everything relating to stake and negotiation should account for $75 \%$ of the job. It's important to recalibrate the phases of the prospective process.

Lets come to the issue of spatializing the great principles. How, once the main territorial injunctions have been established, to help find more local specificities? How do these principles become spatialized in the actions chosen?

N.C.: Precisely, I see there the right cross between the spatial-a geographic reality on a given territory-and the "human intention," in any case the intention of the group, which is not only that of the institutional but also of the civil society. This is where we enter the operational phase. There is the territorial "concrete," the potential and the territorial capital. Béatrice Villari (2012), a researcher at the Milan Politecnico, has developed, in her book on territorial design, the concept of territorial capital, which is the wealth of a territory. This capital is at the crossroads of three spheres-that of entrepreneurs in the broad sense, the sphere of research, and the sphere of governance, of institutions in fact, and it is this matrix that brings them all together and enables them at a given moment to be inspiring for the future of a territory. There is also the notion of heritage and legacy. You draw on a territory for its potentials. The spatial evolves through the actions of the other dimensions of the territorial capital. When it is decided to set up a factory somewhere, it is not the territory that wants it. There are conditions, and the territory allows for these conditions to be met, but it is indeed the decision that makes that the factory will be set up in that place. Which means that the territory prepares the conditions for the human investment. The human and identity dimension is fundamental: to recover old traditions and rework them to plan for a different future, not exactly the same. What is somewhat passed over in silence is the intergenerational transmission of this heritage, the territorial lineage which imprints the collective unconscious, and which makes that sometimes people succeed in reviving their territory.

This reminds me of the project culture which has always guided me. A lecturer of the Nancy school of architecture used to tell us: "First thing when you arrive in a territory or a space for an architectural project, take an interest in the 'already there'." What are the limits, the constraints, how much room for improvement? The "already there" is inspiring. It's when you start from scratch that you are really lost. If you don't work on that principle you create dysfunction. 
There are territorial logics. What I like in territories is that they impose their logics, at a given moment. They are intelligent enough to show us that human intervention, there, was an error and make us understand that it is necessary to repair and make amends.

What is missing as regards prospective in the territories? The needs in geoprospective, on the way of rooting the principles on the spaces so as they are spatially operational and, if possible, effective?

N.C.: A few years ago, I had the opportunity to attend a lecture by Peter Bishop, a futurist at the University of Houston, on the theme of going from prospective to strategy. His presentation on the way to go from idea to action, as the Americans do, was very interesting. You examine whether the action is effective, and if it's not, either you reformulate or you abandon the idea. You have no qualms. You test. I was rather fascinated by that concrete aspect.

I think that we should fairly quickly learn to prioritize prospective orientations that are mature in terms of decision-making, governance, and implementation on the territories, so that you could then field-test them, that is, find an experimentation space, a community, a territory. It is very difficult to apply on a territory orientation of coherent territorial planning scheme that is effective on a Local Urban Plan. For all that, why not do the opposite, while respecting the local or intercommunal town-planning schemes, of course? Namely, choose a territory where the local authorities are game and apply certain orientations on certain projects. Take two or three orientations-climate, biodiversity, for example-, and start, even if the prospective exercise has not been completed. Massify the intentions of projects and practice. If a dysfunction occurs, correct it, have the courage to correct. In an era of experimentation and demonstrators, it could be interesting to create a territorial geoprospective demonstrator, and ask oneself what it is like. We have French experimentation models, like Positive Energy Transition and Green Growth, but on the other hand, you see, we have a European demonstrator such as Nature-Based Solutions which has not always had the expected success in France.

Prospective of the stratospheric kind, brilliant but disconnected, is a preliminary. If you want to adapt it to the territory, you have to delimit it and show that such orientation, when finally applied, is indeed valuable because it is productive. On the other hand, you don't have the complete ecosystem, you don't have the complete dynamics of the prospective exercise. You decide to carry out a one-shot prospective exercise on 1 year, focusing on a specific objective, such as obtaining exceptional water quality within 30 years, for example. You keep only that aspect in a town and you get down to it; you define the interlocutors, and the framework for action allowing to obtain a pollution-free water quality. Big cities do it but it is more difficult for small territories. 
Do you think that you are a lone voice? Or do you feel that other people think the same as you?

N.C.: In the days of Sustainable Territory 2030 and "Penser Autrement les Modes de Vie en 2030" (Think differently about ways of life in 2030), I was feeling very lonely, somewhat atypical, but afterwards I realized that I seemed to be followed within the ministry and in the professional networks that were awakening to these problems. All these questions of nature in the city are widely taken up nowadays. There is great progress. Everything relating to freeing public spaces in town and green requalification of traffic is starting to spread. It is gaining ground with the high authorities, and after that, we know that it percolates... On the whole, things are changing. A lot is happening around urban renaturation or restoring agriculture, especially in peri-urban areas, or technological forms of agriculture. In the United States, they are experimenting on agrihoods ${ }^{10}$ The European commission is also interested in the subject. In particular, it is working on the European green capital, focusing on sustainable territories. The European green capital is determined considering 12 fields, insisting notably on urban agriculture approaches in the field devoted to sustainable territory. It's an interesting factor that the Commission should now take into account to elect a green capital based on new emerging themes, as was not quite the case $3-4$ years ago.

At the moment, there is an array of convergences between those involved in spatial development to include environmental and societal changes, which is promising for the sustainable development of territories.

\subsection{Territorial planning in Europe: the contribution of European Commission Joint Research Centre}

Dr. Carlo Lavalle $(\mathrm{PhD})$ has over 25 years of experience in modeling and data analysis for policy applications. In 1990, he started to work with the Joint Research Centre (JRC) of the European Commission located in Ispra, Italy. He coordinates the development of the LUISA Territorial Modelling Platform and of the European Commission Knowledge Centre for Territorial Policies. The field of expertise of Carlo Lavalle deals with the evaluation of European policies with an integrated and prospective view by taking into account different aspects like economy, transports, and household. In his researches, Carlo Lavalle integrates all types of spaces and environments and all territorial thematic like infrastructures, tourism, transports, demography, and urbanization. The environmental parameters are integrated into

\footnotetext{
${ }^{10}$ Agrihoods, short for "agricultural neighborhoods" are housing developments centered around community farming with the objective to provide access to local food production and healthy living. Planned in suburban and urban spaces, they are an alternative neighborhood growth model.
} 
the model in some specific cases, especially when these parameters can explain the dynamics of territory.

The integration of common European policies in these researches needs to interact strongly with the European Commission in order to have a better representation of the impacts and evolution such policies.

The approach developed into the LUISA Territorial Modelling Platform and of the European Commission Knowledge Centre for Territorial Policies can be applied at different spatial scales, from plots of $100 \mathrm{~m}^{2}$ to the European scale. Carlo Lavalle considers that the change of spatial resolution is both a challenge and a way in order to identify the most relevant drivers of land-use changes according to the scale of the perception of the phenomena. In this frame, the modeling process applies statistical methods based on correlations and spatial analysis in order to understand the relationships between the drivers of land change.

In this case, we can say that the methodology can be considered as spatially explicit as mentioned into the technical report relating to the LUISA model "The final output of LUISA is in the form of a set of spatially explicit indicators that can be grouped according to specific themes, defined as "territorial indicators"” (Lavalle et al., 2017; Jacobs-Crisioni et al., 2017). But some data cannot be considered as "spatially explicit" due to the type of data like the political orientations of the economy.

The integration of future environmental parameters estimated for 2050 and 2100 is also a challenge for the modeling process. Some data are coming from public institutions and organizations like the IPCC (Intergovernmental Panel on Climate Change), others are time series managed by the JRC like remote sensing data.

The Territorial Modelling Platform LUISA aims to evaluate the potential impacts of the European policies and trends on the European territory at local and regional scales. In this frame, LUISA contributed to establish the report on the European Territorial Trends, published in 2017 (Lavalle et al., 2017) that introduces the regional and urban diversities in Europe and their potential development toward 2030.

The spatial representation of the results depends on the European Nomenclature of territorial units for statistics (NUTS) that divides the European territory into subareas according to economic parameters. Three levels are proposed by this classification (Fig. 13.2):

- $\quad$ NUTS 1: major socioeconomic regions, with population thresholds between 3,000,000 and 7,000,000 inhabitants;

- NUTS 2: basic regions for the application of regional policies with population thresholds between 800,000 and 3,000,000 inhabitants;

- NUTS 3: small regions for specific diagnoses with population thresholds between 150,000 and 800,000 inhabitants. 


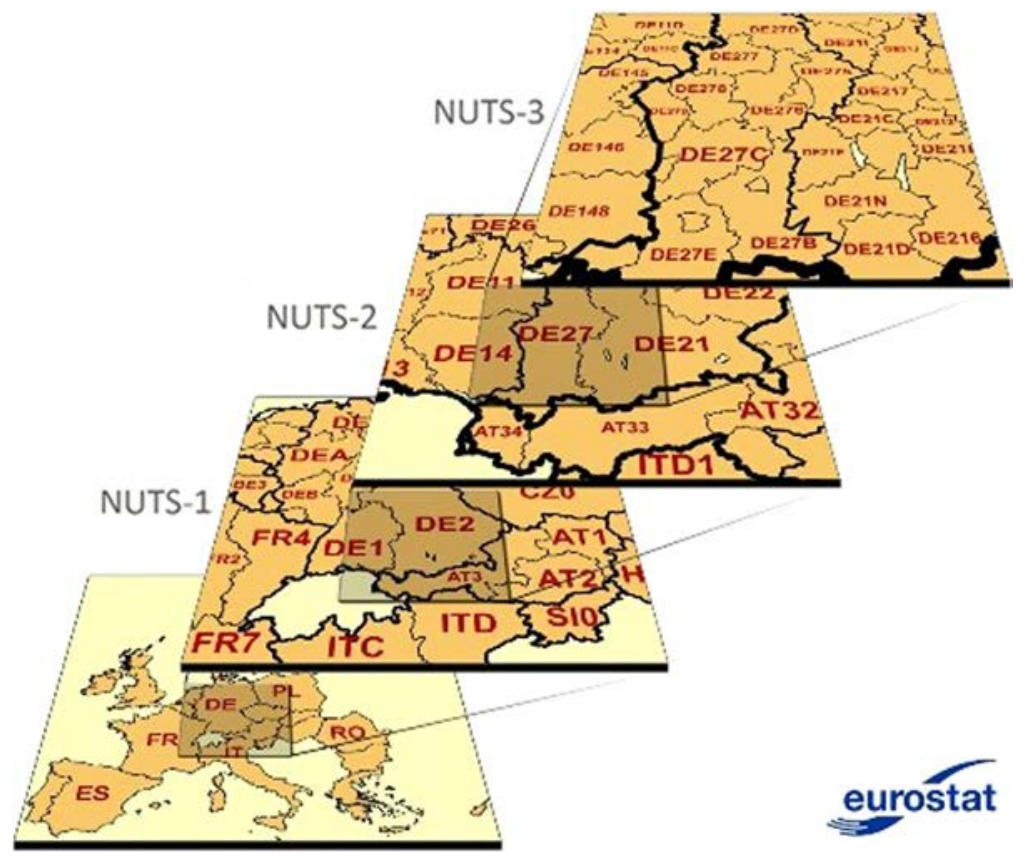

Figure 13.2

Maps of NUTS levels (European Commission Internet site).

In January 2018, the amount of NUTS gathered 104 regions for NUTS 1, 281 regions for NUTS 2, and 1.348 regions for NUTS 3. In order to have statistic data at the lower scale, Eurostat (European Statistical Office) has set up a system of local administrative units (LAUs) compatible with NUTS and called LAU 1 (groups of municipalities but this level is not applied for all European countries) and LAU 2 (municipality level). Some of data integrated by LUISA have been elaborated at the LAU levels. The results provided by LUISA are at the NUTS 2 and 3 levels.

Among the different data that The Territorial Modelling Platform integrates, some of them are related to the public health, the regulatory constraints, the economic drivers, etc. because they have a significant impact on the territorial dynamics. LUISA also incorporates time series in order to identify historical trends and propose current state and future projections of land-use changes. According to these data, LUISA apprehends the interaction between policy scenarios and social, economic, biotic, abiotic, and abiotic drivers in order to propose scenarios of territorial evolution. At the end of this process, LUISA provides results about the demand and the supply concerning the main resources and activities that induce land transformation like housing, infrastructures, transports, industries, energy, biotic, and abiotic resources. The scenarios can be defined as "business as usual" or they 
can focus on the integration of new policies with direct or indirect territorial impacts on the different scales of the study. The comparison between the results of these scenarios and the baseline situation procures a comprehensive frame to estimate the potential impacts of a particular policy.

LUISA is structured according to three main sets:

1. The Territorial Knowledge Base: it gathers data layers with the finest spatial resolution on the main territorial elements and driver like human and industrial settlements, economic indicators, infrastructures, climatic data, and energy;

2. The advanced analytical and modeling modules: it is the core of the modeling platform. It simulates the spatiotemporal dynamics of the main socioeconomic variables at the different scales (NUTS 2 and 3 levels) in order to assess the dynamics of population, production systems, and services;

3. The production and visualization of territorial indicators: LUISA is able to produce spatially explicit indicators grouped in specific themes that are defined as territorial indicators. Among these indicators, we can cite population dynamics, education, health, energy, environment and climate, urban development, social issues, transport and accessibility, employment, etc. Their evolution is computed within 2060 .

It is also possible coupling LUISA with other models that are more specific for the assessment of a particular issue. For example, LUISA has been coupled with the CBM model (Carbon Budget Model of the Canadian Forest Sector, Kurz et al., 2009) in order to assess the potential impacts of future regulation, land dynamics, and climate change on forests, especially in terms of Afforestation/Reforestation, Deforestation, and Forest Management activities (Pilli et al., 2016). The final aim is to assess the potential emissions and removals of $\mathrm{CO}_{2}$ resulting from forest management and use.

Linking LUISA and CBM allowed assessing how much forest biomass could be available given the area for harvest and given the management of forests according to current and future periods.

Fig. 13.3A shows the aggregated data at the scale of Europe concerning the level of conversion of land to forest areas from 2010 to 2030 and Fig. 13.3B, the deforestation for the same time scale.

These results have shown the trends of afforestation and deforestation at the scale of European countries until 2030.

Fig. 13.4 shows a specific example with Germany in order to demonstrate the spatial resolution of the model outputs. 


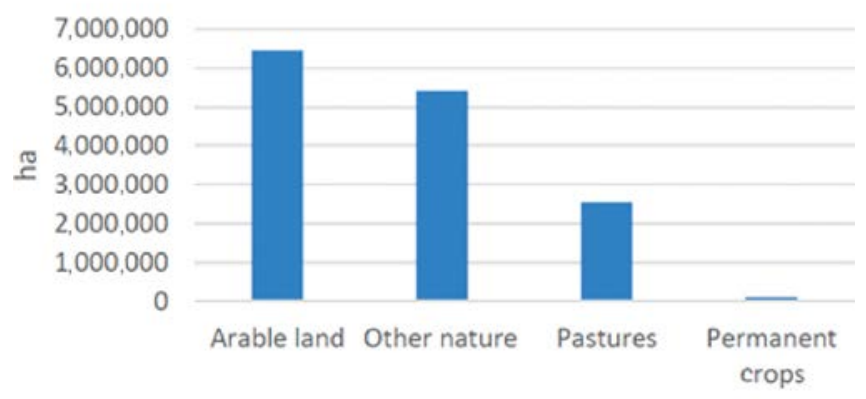

(B)

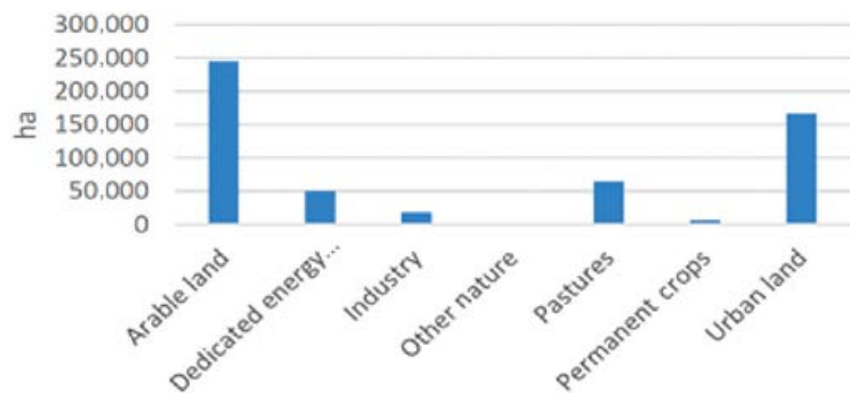

Figure 13.3

Afforestation and deforestation from 2010 to 2030. In EU, (A) Conversion of land to forest land, (B) Conversion of forest land to other land.

Statistics of deforestation and afforestation are also extracted from the selected areas (Fig. 13.5).

Other applications of LUISA have been developed in different topics like energy demand, tourism, agriculture, and water management. This modeling platform represents a generalized approach attesting the need of European Commission to develop models and tools transposable at different scales of perception.

\subsection{Environmental planning in the Mexican territory}

José Juan Hernández Chávez has a Bachelor degree in Biology, of the National School of Biological Sciences of Instituto Politécnico Nacional, México. He is currently studying a master degree in Animal Biology at Sciences Faculty, Universidad Nacional Autónoma de México. He is also a fellow of cohort 20 from LEAD (Leadership for Environment and Development) program México, Colegio de México. His current position is Director for Envionmental Policy in the Secretaría de Medio Ambiente y Recursos Naturales, México where he is in charge of technical counseling and institutional support in the 

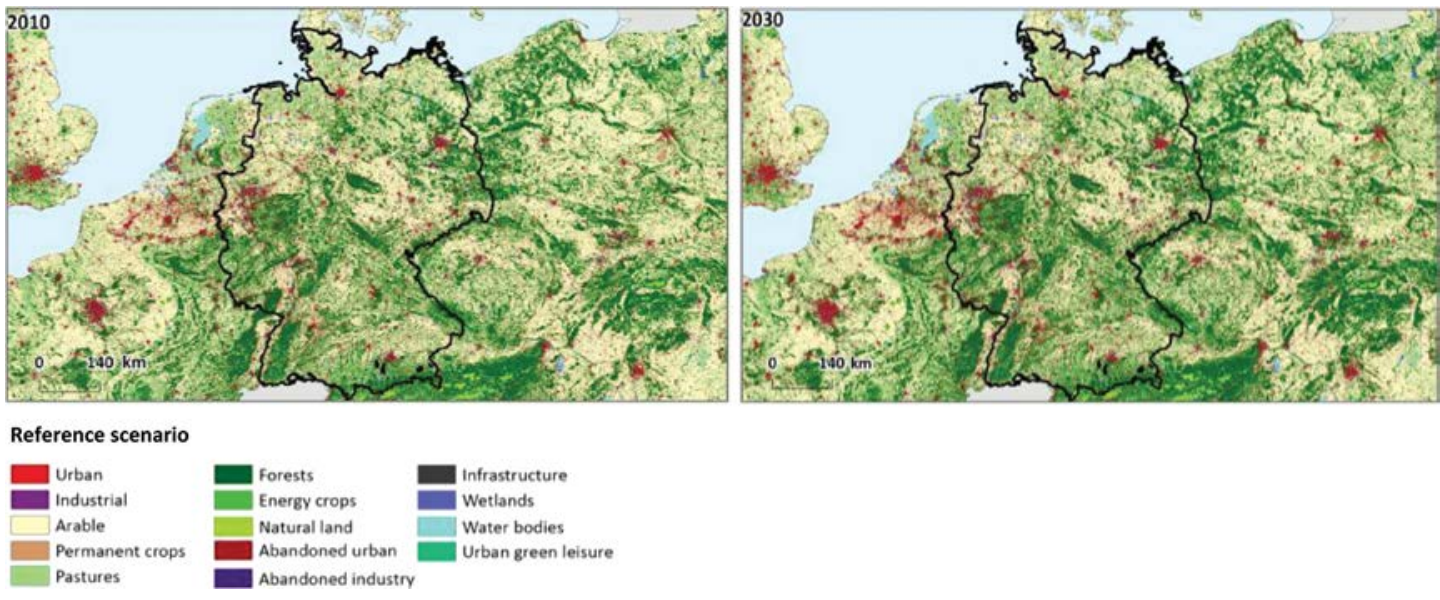

Figure 13.4

Land use observed (2010) and predicted (2030) by the LUISA model.

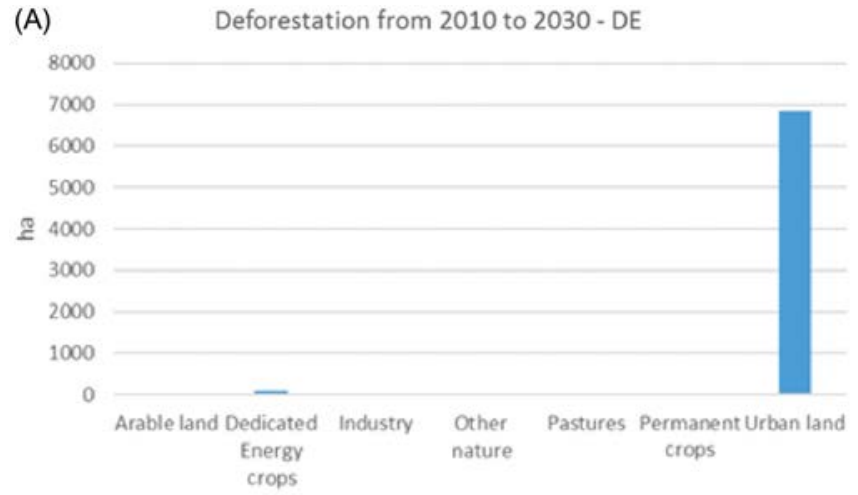

(B) Afforestation from 2010 to $2030-D E$

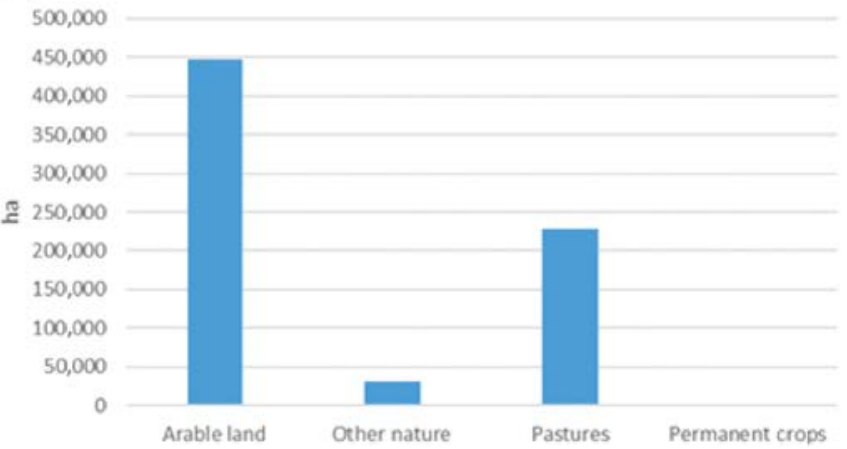

Figure 13.5

Afforestation (A) and deforestation (B) surfaces in Germany, from 2010 to 2030. 
processes of environmental planning (ordenamiento ecológico del territorio) in the Mexican Territory.

According to the interview in January 2020, José Juan Hernandez Chávez explained his vision of ecological land planning in Mexico that requires a prospective approach in order to integrate the potential evolution of the territory. He shares with us his opinion on how a geoprospective approach should play a role in territorial planning in Mexico, according to the challenge of biodiversity and nature protection.

Do you know the concept of geoprospective?

Geoprospective can be understood as a conceptual and methodological framework used as a guide to perform an alternative scenario of a future environmental state for a territory, in order to use them as tools, to figure out how to make a management of natural resources with a time reference. In the geoprospective research, you should have to follow some general rules:

- The future is unpredictable, but we can make an educated assumption (hypothesis) of trends of the future based on the discovery and interpretation of historical patterns.

- The reality is complex, interrelated, and nonlinear, so you must bear in mind those issues when you give an interpretation of the data.

- Keep in mind that high correlations in patterns not necessarily mean causality among them.

- Always try to make a cross-check between geographic and tabular data available.

How the spatial dimension is taken into account in your activities in prospective, especially concerning the evolution of the territorial structures?

For the environmental planning in México (known as Ordenamiento ecológico del territorio in the Mexican law), the spatial dimension is a strategic matter. The main issue is modeling the change through time of spatial variables like the land uses (including native and anthropogenic ecosystems), the identification of biodiversity spots (high number of species or distribution of endangered species in our country), soil erosion, carbon sequestration, and water captured to the aquifers. The rates of modeled change are used to develop thresholds in the use of natural resources.

On what topic is addressed your activity about prospective? That is, evolution of an ecosystem or many ecosystems? Evolution of the spatial distribution of species, etc.?

The main topics of prospective are the evaluation landscape changes, changes of income of people due to a change in ecosystem services (erosion, pollution, water quality, loss of biodiversity, etc.) which is a real challenge due to the complexity and interconnectivity of these dimensions that characterize our socioecosystems. 
Table 13.1: Methodology for land suitability assessment integrating stakeholders' participation.

\begin{tabular}{|c|c|c|c|}
\hline Steps & Activities & People involved & Means \\
\hline 1 & Definition of objectives and goals & Stakeholders & Lectures \\
\hline 2 & Methods for suitability analysis & Interdisciplinary team & Lectures \\
\hline 3 & Sectorial objectives and goals & $\begin{array}{l}\text { State and municipal authorities and } \\
\text { stakeholders representatives }\end{array}$ & Lectures \\
\hline 4 & Description of activities & Stakeholders representatives & $\begin{array}{l}\text { Small group } \\
\text { involvement }\end{array}$ \\
\hline 5 & Identification of land-use criteria & Stakeholders representatives & $\begin{array}{l}\text { Small group } \\
\text { involvement }\end{array}$ \\
\hline 6 & $\begin{array}{l}\text { Identification of environmental } \\
\text { conflicts }\end{array}$ & $\begin{array}{l}\text { Stakeholders representatives and State and } \\
\text { municipal authorities }\end{array}$ & $\begin{array}{l}\text { Small group } \\
\text { involvement }\end{array}$ \\
\hline 7 & $\begin{array}{l}\text { Identification of compromises for } \\
\text { settlement of conflicts }\end{array}$ & $\begin{array}{l}\text { Stakeholders representatives and State and } \\
\text { municipal authorities }\end{array}$ & $\begin{array}{l}\text { Small group } \\
\text { involvement }\end{array}$ \\
\hline
\end{tabular}

Based on Bojórquez-Tapia, L.A., Díaz Mondragón S., Ezcurra E., 2001. GIS-based approach for participatory decision making and land suitability assessment. Int. J. Geogr. Inf. Sci. 15 (2), 129-151.

On what kind of geographical scales is based your approach? (Microstation, municipality, watershed, regional, national, international)

In Mexico, the environmental law establishes a hierarchy of planning, from national to municipality levels, including the marine territory. In each level, there is a set of criteria mixing geomorphology, edaphology, basins, sub and microbasin and vegetation types used to create a nested arrangement of polygons. In general terms, for the national and marine level the working scale is 1:1,000,000, for the regional level 1:250,000, and for the local level is 1:50,000. But, sometimes when it is relevant, we use multiscale information as complement for specific purposes.

Does your methodology can be considered as systemic? If yes, what are the main methods you use?

Yes, indeed. The methodology for the environmental planning (Ordenamiento ecológico del territorio) in México was created from an academic research, ${ }^{11}$ the main concepts of the methodology were included in a regulatory law ${ }^{12}$ and finally the specific methods were published in the «Manual del Proceso de Ordenamiento Ecológico del Territorio $\gg$.

Table 13.1 shows the different steps proposed by Bojórquez-Tapia et al. (2001) in order to integrate stakeholders' participation in ecological planning of the territory.

11 Bojórquez Tapia, L. A., Díaz Mondragóny, S., Saunier R., 1997. Ordenamiento Ecológico de la costa norte de Nayarit. Instituto de Ecología, UNAM, Organización de los Estados Americanos Departamento de Desarrollo Regional y Medio Ambiente.

12 Reglamento en materia de ordenamiento ecológico de la Ley General del Equilibrio Ecológico y la Protección al Ambiente de México. 
After the integration of such data, the methodology uses a multivariate statistical procedure for classifying land units into land suitability groups, according to the different sectors. This methodology of land suitability assessment based on multicriteria analysis is described by Bojórquez-Tapia et al. (1994).

Do you analyze the spatial interactions between some parameters of the territory (water, animals, floral, climate, etc.)?

The core of the methodology is the «Análisis de Aptitud Sectorial»; it consists in a geographic exploration of the interactions in the territory conducted by the stakeholders (farmers, cattle ranchers, mining owner, industrial developers, etc.) and translated into a Geographic Information System (GIS) in order to achieve cartography of aptitude gradients in the territory for each interest sector. Also, there are methods called «conflict analysis » between stakeholder and «Area identification for conservation and compensation of negative environmental impacts $\gg$.

All this cartographic information is the input for the prospective (sensu stricto) that includes modeling and simulations of social-environmental systems with software (STELLA or others) in order to describe and quantify future scenarios.

According to your experience, what are the limits of the methods that you use and what kind of approaches and results should be relevant in order to help you?

The limits of the methodology of «Ordenamiento Ecológico del Territorio » are the following:

- Public participation is low because there are few time and resources in order to involve the citizen opinion and vision.

- It doesn't perform a landscape analysis that includes issues like fragmentation, corridors, matrix permeability, relaxation effect, and border effect. Those elements have a strong impact on nature, ecosystems services, and biodiversity conservation.

- It doesn't perform an evaluation of the effect of climate change in the vegetation and the «aptitud sectorial 》, which is a significant challenge in territorial planning due to our context of climate forcing.

- It didn't define the maximum amount of native vegetation change, which is also a significant parameter to take into account in territorial planning.

- It doesn't include the socioeconomic issues in the environmental planning program, which is another major dimension according to the dynamics of socioecosystems.

Does your institution seek to establish projections in order to adapt the public policies according to global changes?

Yes, definitely. The formulation process of the Ordenamiento Ecológico del Territorio have a set of analysis to predict paths for some variables like rates in landscape change, water 
consumption, and population grow. This analysis is elaborated with tabular information and GIS. The main reason is to establish thresholds in the use of natural resources.

Does the concept of resilience is integrated into your activities and the reflection of territorial planning currently? If yes, how? If not, is it considered as implicit?

The resilience is a topic not included in the environmental planning process, but it could be considered as an issue in the climate change adaptation.

\section{Acknowledgments}

Christine Voiron and Emmanuel Garbolino want to express their gratefulness to Nathalie Cecutti, Carlo Lavalle, and José Juan Hernández Chávez for the time they dedicated to these interviews and for sharing all of these interesting information and data.

\section{References}

Bojórquez-Tapia, L.A., Ongay-Delhumeau, E., Ezcurra, E., 1994. Multivariate approach for suitability assessment and environmental conflict resolution. J. Environ. Manag. 14, 187-198.

Bojórquez-Tapia, L.A., Díaz Mondragón, S., Ezcurra, E., 2001. GIS-based approach for participatory decision making and land suitability assessment. Int. J. Geogr. Inf. Sci. 15 (2), 129-151.

CGDD, Mission prospective, Le programme Territoire 2030. <http://www.territoire-durable-2030. developpement-durable.gouv.fr/index.php/td2030/programme/?id = aqua $>$ (in French).

Commissariat Général au Développement Durable, 2013, Biodiversité et Territoires 2030, cinq scénarios d'évolution, synthèse de l'exercice de prospective : volets 1 et 2, Collection Etudes \& Documents de la Délégation au Développement Durable, $\mathrm{n}^{\circ}$ 86, juin 2013 (in French).

Hervieu, H., Jannès-Ober, E., 2017. L'exercice Aqua 2030: comment imaginer les politiques de demain sur l'eau et les milieux aquatiques à la fois dans ses dimensions nationale et territoriale? Sci. Eaux Territ. 22, 62-67 (in French).

Jacobs-Crisioni, C., Diogo, V., Perpiña Castillo, C., Baranzelli, C., Batista e Silva, F., Rosina, K., et al., 2017. The LUISA Territorial Reference Scenario 2017: A Technical Description. Publications Office of the European Union, Luxembourg, ISBN 978-92-79-73866-1, doi:10.2760/902121, JRC108163. 42p.

Kurz, W.A., Dymond, C.C., White, T.M., Stinson, G., Shaw, C.H., Rampley, G.J., et al., 2009. CBM-CFS3: a model of carbon-dynamics in forestry and land-use change implementing IPCC standards. Ecol. Model. 220, 480-504.

Lavalle, C., Pontarollo, N., Batista E Silva, F., Baranzelli, C., Jacobs, C., Kavalov, B., et al., 2017. European Territorial Trends. Facts and Prospects for Cities and Regions Ed. 2017, EUR 28771 EN. Publications Office of the European Union, Luxembourg, ISBN 978-92-79-73428-1, doi:10.2760/148283, JRC107391. $62 \mathrm{p}$.

Pilli, R., Fiorese, G., Abad Viñas, R., Rossi, S., Priwitzer, T., Hiederer, R., et al., 2016. LULUCF Contribution to the 2030 EU Climate and Energy Policy; EUR 28025. Publications Office of the European Union., Luxembourg, JRC102498; doi:10.2788/01911.- 690p.

Villari, B., 2012. Design per il territorio. Un Approccio Community Centred. Ed. Franco Angeli, Milan (in Italian). 